\title{
EXPERIMENTAL AND NUMERICAL INVESTIGATION OF THE DEEP DRAWING PROCESS FOR AN AUTOMOBILE PANEL AND PREDICTION OF APPROPRIATE AMOUNT OF PARAMETERS BY MULTI-LAYER NEURAL NETWORK
}

\author{
Saeed Sirous Najafabadi \\ Young Researchers and Elite Club, Najafabad Branch, Islamic Azad University, Najafabad, Iran \\ e-mail: saeed.sirous89@gmail.com \\ Ali Talebi Anaraki \\ Department of Mechanical Engineering, Najafabad Branch, Islamic Azad University, Najafabad, Iran \\ MEHran Moradi \\ Department of Mechanical Engineering, Isfahan University of Technology, Isfahan, Iran.
}

\begin{abstract}
In this paper, the deep drawing process of an automobile panel in order to select the appropriate amount of parameters has been investigated. The parameters include friction between the blank and die, blank width and length, blank thickness and gap between the blank and blank-holder. A multi-layer artificial neural network (ANN) trained by finite element analyses (FEA) is applied in order to improve forming parameters and achieve a better quality. As the FEA results are used to train the ANN, the FEA results have been verified by three experiments. Finally, an appropriate amount of each parameter is predicted by the trained ANN and a FEA has been done based on the ANN prediction to evaluate the accuracy of the trained ANN. Moreover, it is shown that the ANN could predict results within a 10 percent error. In addition, the proposed method for prediction of the appropriate parameters (ANN) is confirmed by comparing with the Taguchi design of experiment prediction. It is also shown that the model obtained by the former method has lower errors than the latter one. In this study, the Taguchi model is used to evaluate the effect of parameters on tearing and wrinkling. Based on the Taguchi design of experiment, while the blank length is the most effective parameter on tearing, the maximum height of wrinkles on flanged parts mainly depends on the blank thickness.
\end{abstract}

Keywords: deep drawing, finite element analysis (FEA), multi-layer artificial neural network (ANN), Taguchi design

\section{Introduction}

Sheet metal forming is one of the most widely used industrial processes, which is fast and cost-effective. Deep drawing, which is widespread among other sheet metal forming processes, is used for a wide variety of industrial purposes. In the deep drawing process (Fig. 1), the blank is positioned on a die. Then, the blank-holder places the blank at a certain position and the punch forms the blank with a downward movement. There are lots of parameters that affect the deep drawing process and quality of the final product such as geometry of the forming tool, punch and blank-holder force, friction, blank dimensions, and material properties (Singh and Agnihotri, 2015; Fereshteh-Saniee and Montazeran, 2003). These parameters affect the appearance of the final product. Adjustment of each mentioned parameter might prevent forming defects such as tearing, wrinkling, thinning, earing, and springback. Therefore, selection and optimization of the process parameters is an effective way to form the blank with better appearance, in a cost effective way and without any defects. 

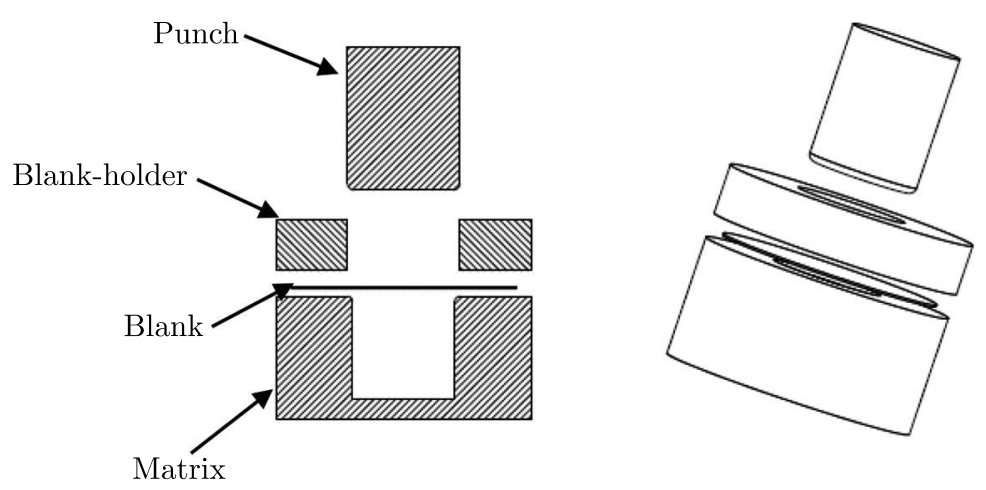

Fig. 1. Schematic of the deep drawing process

Colgan and Monaghan (2003) tried to find effective parameters based on a statistical method using orthogonal arrays. They conducted an experiment on four hundred steel parts with $1 \mathrm{~mm}$ thickness. The results showed that the punch radius and matrix radius were the main effective parameters in final thickness. They reported that smaller punch edge radius needed more force and it was shown that the lubricant type affected the punch force significantly. In addition, in a recent research by Laurent et al. (2015) warm deep drawing of AA5754-O alloy was investigated. They manufactured a warm die for their experiment and studied the influence of temperature on springback. They conducted their experiments between room temperature and $200^{\circ} \mathrm{C}$. In their research, Abaqus/Explicit was used to simulate the procedure in which an anisotropic temperature-dependent model was utilized. Furthermore, they verified the simulation results using an experiment.

Sezek et al. (2010) studied the effect of deep drawing factors such as die radius, friction and blank thickness both numerically and experimentally. The results showed that the friction coefficient and the blank-holder angle were main factors. They also concluded that the drawing ratio was reduced by increasing the die angle and the results of experiment were close to the simulation. Demirci et al. (2008) investigated deep drawing parameters for Al1050 alloy by both FEA and experiment. They focused on the blank-holder force and thickness distribution in the drawn part.

Chamekh et al. (2009) used trained ANN to investigate the anisotropy behavior based on FEA results. A back propagation ANN was implemented in their study and the results of FE were in good agreement with the results of ANN. They declared that the combination of ANN and FE could be used to optimize the deep drawing process. Moreover, Forouzan and Akbarzadeh (2007) utilized a back propagation ANN to predict some material properties such as yield stress, elongation, ultimate stress and average of anisotropy for rolled AA3004 aluminum alloy. The maximum percentage of error was estimated about 6.35 by trained ANN. Finally, they inferred that mechanical properties and anisotropy of the material were predictable by using their method.

El Sherbiny et al. (2014) investigated changes in thickness and residual stress in the deep drawing process. Their paper analyzed the process by using FEA. The results of simulation were verified by experimental results. In their article, geometrical parameters were radius of the matrix edge, radius of the punch edge and the friction coefficient. They investigated the effect of the mentioned parameters on the drawn blank in 8 sections. The maximum amount of residual stress was also measured. Furthermore, Padmanabhan et al. (2007) investigated the effect of three parameters including matrix radius, blank-holder force and friction coefficient in deep drawing of symmetric parts. They combined the FE method with the Taguchi method. The results showed that the most effective parameter in thickness distribution was the matrix edge radius which was followed by the blank-holder force and the friction coefficient. 
Yagami et al. (2007) investigated the effect of blank-holder motion on formability factors such as wrinkling and drawing of a copper blank during the deep drawing process. They designed an algorithm that controlled the process and compared the results with finite element simulation. The results illustrated that the wrinkles which were lower than $200 \mu \mathrm{m}$ could be omitted. Furthermore, the FE results reported improvement of the formability and reduction of the ductile damage behavior. Additionally, Zein et al. (2014) analyzed a typical deep drawing die and focused on improving finial dimensions using plastic return. First, they verified the FEA with experiments. Then, they changed a single parameter while other parameters were kept constant, and repeated the finite element simulation trying to optimize the main parameters such as matrix edge radius, punch radius, blank thickness and clearance. Finally, optimum amounts were suggested for main parameters.

Candra et al. (2015) investigated the variable blank-holder force during punch motion in order to prevent tearing. In their research, they used FEA with a slab method. Although their results contained slight errors, they inferred that the presented method assisted to prevent the sheet from tearing during the deep drawing process. Fereshteh-Saniee and Montazeran (2003) studied the drawing force using analytical, numerical, and experimental methods. They investigated the effect of element type on the drawing force and strain alteration and studied the effect of friction coefficient on the force-displacement diagram using the Finite Element Method. It was also inferred that the Sieble equation could estimate the results more accurate than other analytical methods and proved that the Sieble equation was more sensitive to the friction coefficient than FEA. Finally, by comparing FE results with experimental results, it was determined that shell elements estimated more accurate results than four-node elements.

Singh et al. (2011) conducted a research on optimum amounts for the matrix and punch radius, friction coefficient and drawing ratio for St14 blank with $1 \mathrm{~mm}$ thickness. They obtained optimum amounts using 28 experiments, neural network and genetic algorithm coupling. In an comprehensive study, Wifi and Abdelmaguid (2012) worked on a review article introducing optimization methods for both single and progressive dies.

In this paper, by using artificial neural network trained by FEA results, an appropriate amount of each parameter is selected in three steps. First, FEA is done and verified by three experiments. Second, the ANN is trained based on the design of experiment data. Third, the appropriate amount of each parameter is found using the trained ANN. These three steps are shown in Fig. 2. The main parameters which are selected to be investigated are the friction between matrix, blank-holder and blank, friction between punch and blank, blank width and length, blank thickness and the gap between blank and blank-holder. In addition, outputs which are defined as impact indicators are tearing and wrinkling.

\section{Simulation of the deep drawing process}

\section{1. $\quad$ Finite Element modeling}

As it can be seen in Fig. 3, four parts are modeled in the Finite Element software. These parts include the blank, punch, matrix, and blank-holder. Due to symmetry of the matrix, half of it has been modeled in Abaqus/Explicit. The punch, matrix, and blank-holder are assumed to be discrete rigid parts and their displacements are controlled by reference points. The mesh used in this simulation is R3D3 which means 3 points and 3 dimensional solid elements.

The blank is the only deformable part which is meshed by S4R shell elements. S4R means four points with reduced integration. These meshes are suitable for simulation of sheet behavior with respect to thickness variation (Abaqus v. 6.11). 


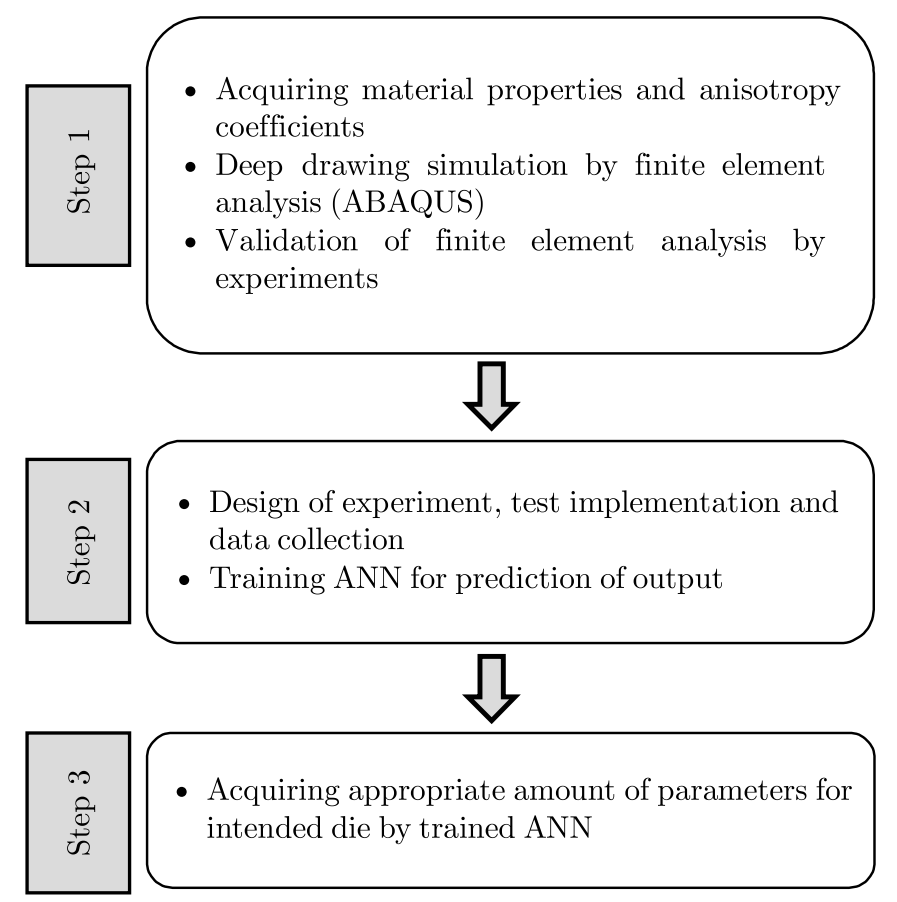

Fig. 2. Proposed steps in the investigation

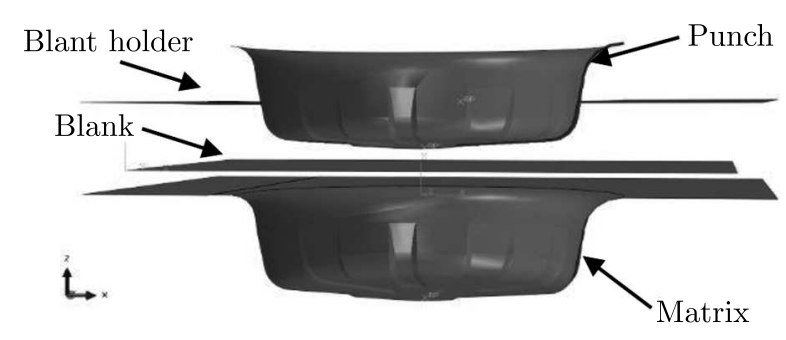

Fig. 3. Defined parts used in FE simulation

\subsection{Material properties}

A deformable St14 blank is analysed in this article. The chemical composition of this material is shown in Table 1. Its stress-strain curve is evaluated with INSTRON 4486 simple tensile test machine under ASTM E8 standard and $0.8 \mathrm{~mm}$ sheet thickness (Fig. 4a). Mechanical properties are demonstrated in Table 2. It should also be noted that values of anisotropy have been calculated with the Hill criterion which is shown in formula as

$$
R_{22}=\sqrt{\frac{r_{90}\left(r_{0}+1\right)}{r_{0}\left(r_{90}+1\right)}} \quad R_{33}=\sqrt{\frac{r_{90}\left(r_{0}+1\right)}{r_{90}+r_{0}}} \quad R_{12}=\sqrt{\frac{3 r_{90}\left(r_{0}+1\right)}{\left(2 r_{45}+1\right)\left(r_{0}+r_{90}\right)}}
$$

The values of $R_{11}, R_{13}$ and $R_{23}$ are equal to 1 .

Table 1. Chemical composition of St14 [wt\%]

\begin{tabular}{|c|c|c|c|c|}
\hline $\mathrm{C}$ & $\mathrm{Mn}$ & $\mathrm{S}$ & $\mathrm{P}$ & $\mathrm{Al}$ \\
\hline \hline 0.037 & 0.222 & 0.03 & 0.05 & 0.061 \\
\hline
\end{tabular}

Furthermore, to evaluate tearing, the FLD criterion is used. The FLD diagrams are found from the library of Autoform software (Fig. 4b). It has been assumed that thickness differentials have not affected the FLD (Hashemi et al., 2012). 
Table 2. Mechanical properties of St14

\begin{tabular}{|l|c|}
\hline \multicolumn{1}{|c|}{ Parameters } & Value \\
\hline \hline Density, $\rho$ & $7800 \mathrm{~kg} / \mathrm{m}^{3}$ \\
\hline Young's modulus, $E$ & $210 \mathrm{GPa}$ \\
\hline Poisson's coefficient, $\nu$ & 0.3 \\
\hline Yield Stress, $\sigma$ & $169.54 \mathrm{MPa}$ \\
\hline Ultimate Stress, UTS & $520 \mathrm{MPa}$ \\
\hline$r_{0}$ & 1.87 \\
\hline$r_{45}$ & 1.3 \\
\hline$r_{90}$ & 2.14 \\
\hline
\end{tabular}
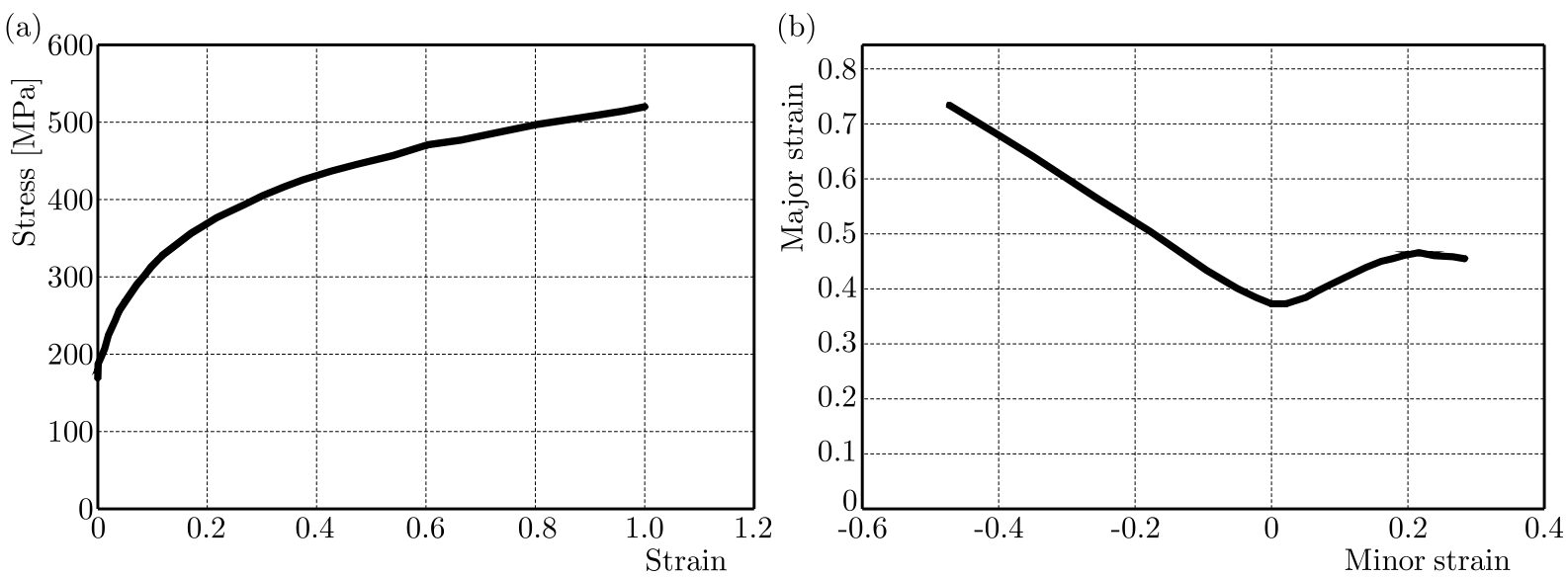

Fig. 4. (a) Stress-strain graph for St14, (b) FLD graph for St14

\subsection{Validation of FEA results}

Validation of FEA results is done in three steps. These steps are mesh independence and include investigation of energy graphs and comparison between FEA and experiments. Regarding the mesh independence, as can be seen in Table 3, several analyses with different mesh sizes are done. Meshes are sized from $3 \mathrm{~mm}$ to $14 \mathrm{~mm}$ and the results showed that 8,10 and $12 \mathrm{~mm}$ meshes lead to similar results. Therefore, for precise estimation and optimization of the analysis time, a $10 \mathrm{~mm}$ mesh has been used. In the second part of the validation, in which energy graphs were scrutinized, kinetic energy and artificial energy graphs were compared with internal energy. Finally, in the third part of the validation, FEA results were compared with three specimens drawn in different circumstances.

Table 3. Independence of the mesh size

\begin{tabular}{|c|c|c|c|c|c|}
\hline $\begin{array}{c}\text { Mesh size } \\
{[\mathrm{mm}]}\end{array}$ & $\begin{array}{c}\text { Number of } \\
\text { element }\end{array}$ & $\begin{array}{c}\text { Number of } \\
\text { node }\end{array}$ & $\begin{array}{c}\text { Time } \\
\text { resolution }[\mathrm{s}]\end{array}$ & $\begin{array}{c}\text { STH } \\
{[\mathrm{mm}]}\end{array}$ & FLD \\
\hline \hline 3 & 97200 & 97844 & 26640 & 0.416 & 1.250 \\
\hline 4.5 & 43254 & 43684 & 11435 & 0.652 & 0.919 \\
\hline 5.5 & 28994 & 29346 & 6756 & 0.606 & 0.906 \\
\hline 6 & 24400 & 24723 & 4192 & 0.679 & 0.815 \\
\hline 8 & 13650 & 13892 & 2216 & 0.687 & 0.805 \\
\hline 10 & 8760 & 8954 & 1354 & 0.701 & 0.793 \\
\hline 12 & 6100 & 6262 & 856 & 0.727 & 0.707 \\
\hline
\end{tabular}


Regarding the third part of validation, Fig. 5 shows the drawing result for the first specimen in which wrinkles occurs on the flanging part and wall of the specimen both in the experiment and FEA. The input parameters for this experiment are $0.3 \mathrm{~mm}$ gap between the blank-holder and blank, $0.8 \mathrm{~mm}$ blank thickness, $1200 \times 1460 \mathrm{~mm}$ blank size. Lubricant films between the punch and blank and a piece of plastic between the matrix, blank-holder and blank are taken into account used. It should be noted that the friction coefficient is selected based on the previous studies (Colgan and Monaghan, 2003; Watiti and Labeas, 2010; Gao et al., 2010). In the second experiment, shown in Fig. 6, all parameters except the gap between blank-holder and blank remained constant. As the gap was closed for drawing the second specimen, tearing occurred in FEA and the experiment. In FEA, the elements with the FLD criterion higher than 1 were eliminated to show tearing. Finally, in the third experiment, increasing the gap up to $0.05 \mathrm{~mm}$ resulted in thorough drawing without tearing and severe wrinkling. As shown in Fig. 7 and Table 4, thickness and wrinkling in the third drawing specimen are evaluated by FEA and experimentally.
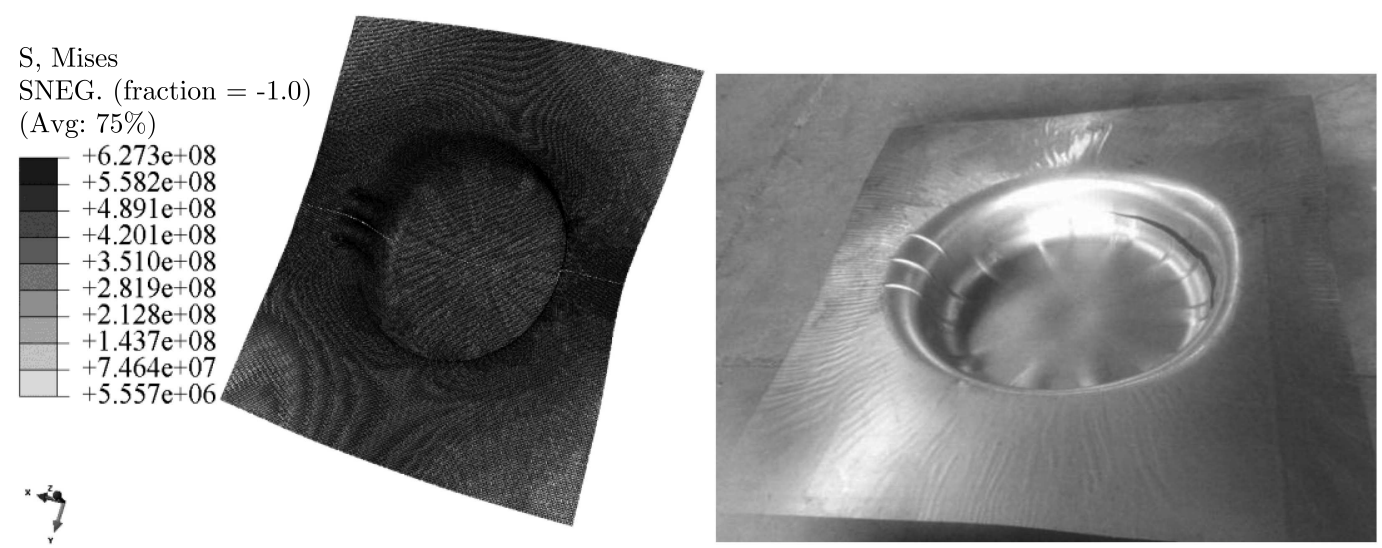

Fig. 5. Comparison between finite element analysis and experiment for the first sample

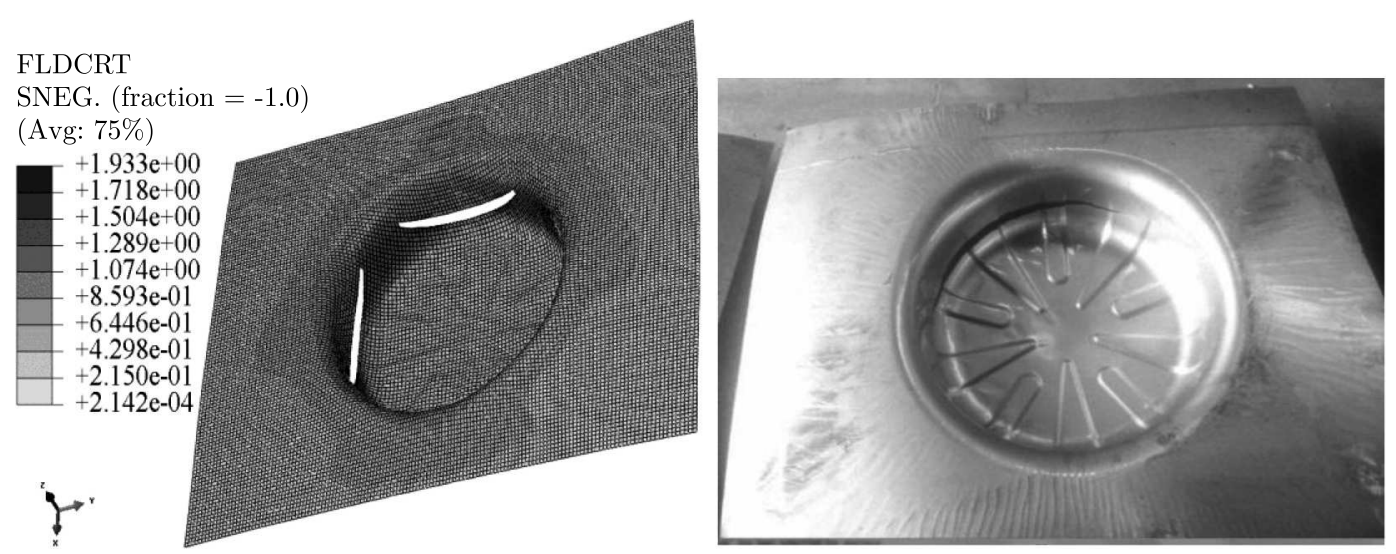

Fig. 6. Comparison between finite element analysis and experiment for the second sample

Table 4. Comparison of wrinkling length between experiment and FEA for the third sample

\begin{tabular}{|c|c|c|c|}
\hline $\begin{array}{c}\text { Wrinkling location } \\
\text { based on Fig. 3 }\end{array}$ & $\begin{array}{c}\text { Experiment } \\
{[\mathrm{mm}]}\end{array}$ & $\begin{array}{c}\text { FEA } \\
{[\mathrm{mm}]}\end{array}$ & $\begin{array}{c}\text { Error } \\
{[\%]}\end{array}$ \\
\hline \hline Wrinkling length (left) & 1.75 & 1.90 & 8.21 \\
\hline Wrinkling length (right) & 1.55 & 1.67 & 7.45 \\
\hline
\end{tabular}




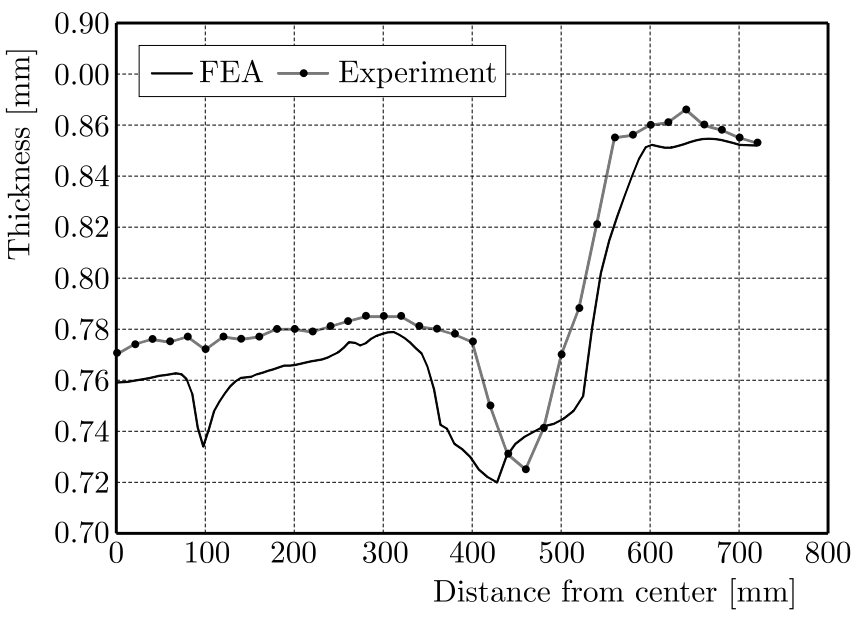

Fig. 7. Comparison of thickness between finite element analysis and experiment for the third sample

Given the validation procedure, it can be concluded that FEA results are precise. Therefore, these results could be used to train an ANN.

\section{Modeling}

\subsection{Design of the experiment}

After determination of six influential parameters in the final step of panel production, each parameter is defined in three levels based on a multiple experiment and FEA. As it can be seen in Table 5, these parameters include friction between the blank and die surface, blank width, blank length, blank thickness and blank-holder gap.

Provided that the design of experiment was based on the full factorial design, 729 experiments should be done which was time consuming. Therefore, the method of training an ANN has been used to determine an appropriate amount of each parameter. The Taguchi method was utilized to evaluate the effect of each parameter on tearing and wrinkling. Based on the number of parameters and their levels in the Minitab software, it was determined that the L27 model should be used for the Taguchi design of the experiment.

Table 5. Input parameters and selected levels

\begin{tabular}{|c|c|c|c|c|}
\hline Parameters & Factor number & Level 1 & Level 2 & Level 3 \\
\hline \hline Friction matrix/blank-holder and blank & Factor 1 & 0.04 & 0.07 & 0.1 \\
\hline Friction punch and blank & Factor 2 & 0.04 & 0.07 & 0.15 \\
\hline Blank width & Factor 3 & 1150 & 1200 & 1250 \\
\hline Blank length & Factor 4 & 1360 & 1460 & 1560 \\
\hline Blank thickness & Factor 5 & 0.7 & 0.8 & 0.9 \\
\hline Blank-holder gap & Factor 6 & 0.02 & 0.05 & 0.07 \\
\hline
\end{tabular}

\section{2. $\quad$ Training an artificial neural network}

ANN is an effective method for solving problems in which relationships between parameters are complex or defining them in one formula is difficult. In the deep drawing process, numerous parameters exist and an analytical formula could not explain them. In the present research, a network with 2 hidden layers is utilized. The first hidden layer has 10 neurons with the 
sigmoid transfer function, and in the second hidden layer a linear transfer function is used. The neural network is a feed-forward network which uses the back propagation error algorithm and the Levenberg-Marquardt training algorithm and in order to train it 109 data are used. The network is selected based on testing a wide variety of networks with different numbers of layers and available training algorithms.

As it is obvious in Fig. 8, there are six input parameters in the first layer and two outputs including the value of the FLD criterion and maximum wrinkling height. Figure 9 illustrates the training process with the best performance in the first epoch and the training process terminated after six epochs. It can be seen that the precision of the network with respect to validation data has been decreased after the first epoch. Figure 10 shows the regression graph of the trained network. In this graph, values of $R$ near 1 reveal network precision and, more importantly, the similar $R$ values for training data, test data and validation data indicate that this network does not memorize the training data.

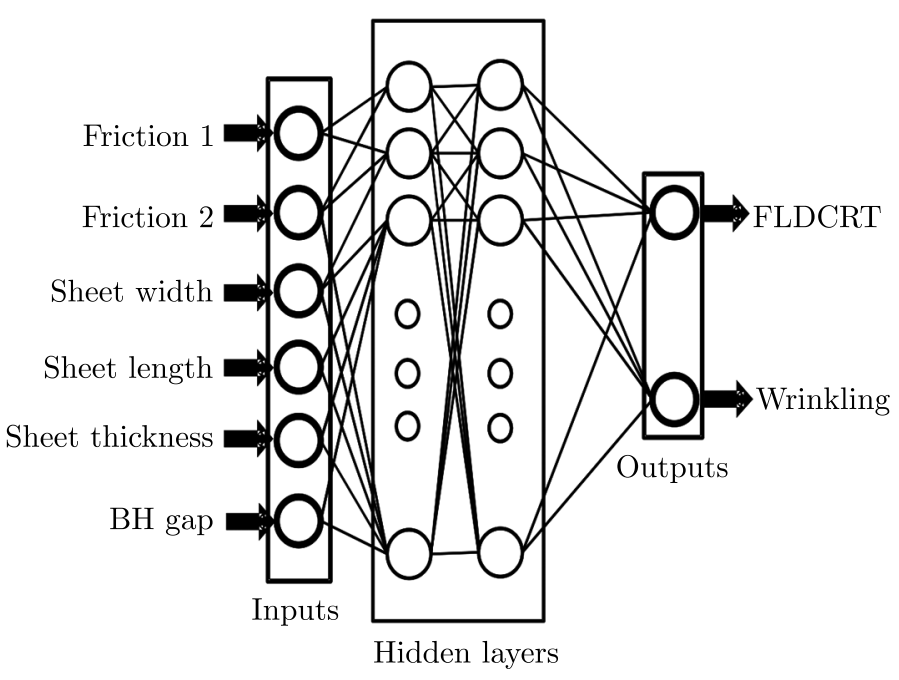

Fig. 8. Schematic of the applied artificial neural network

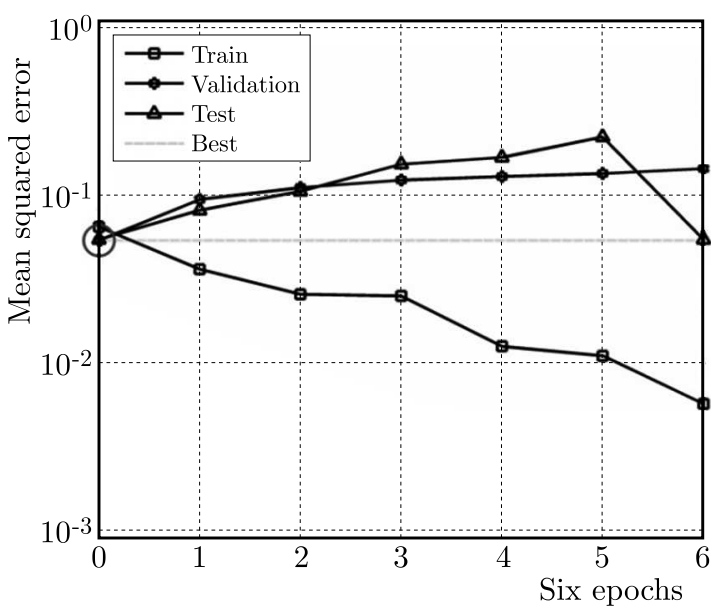

Fig. 9. Training process of artificial neural network 

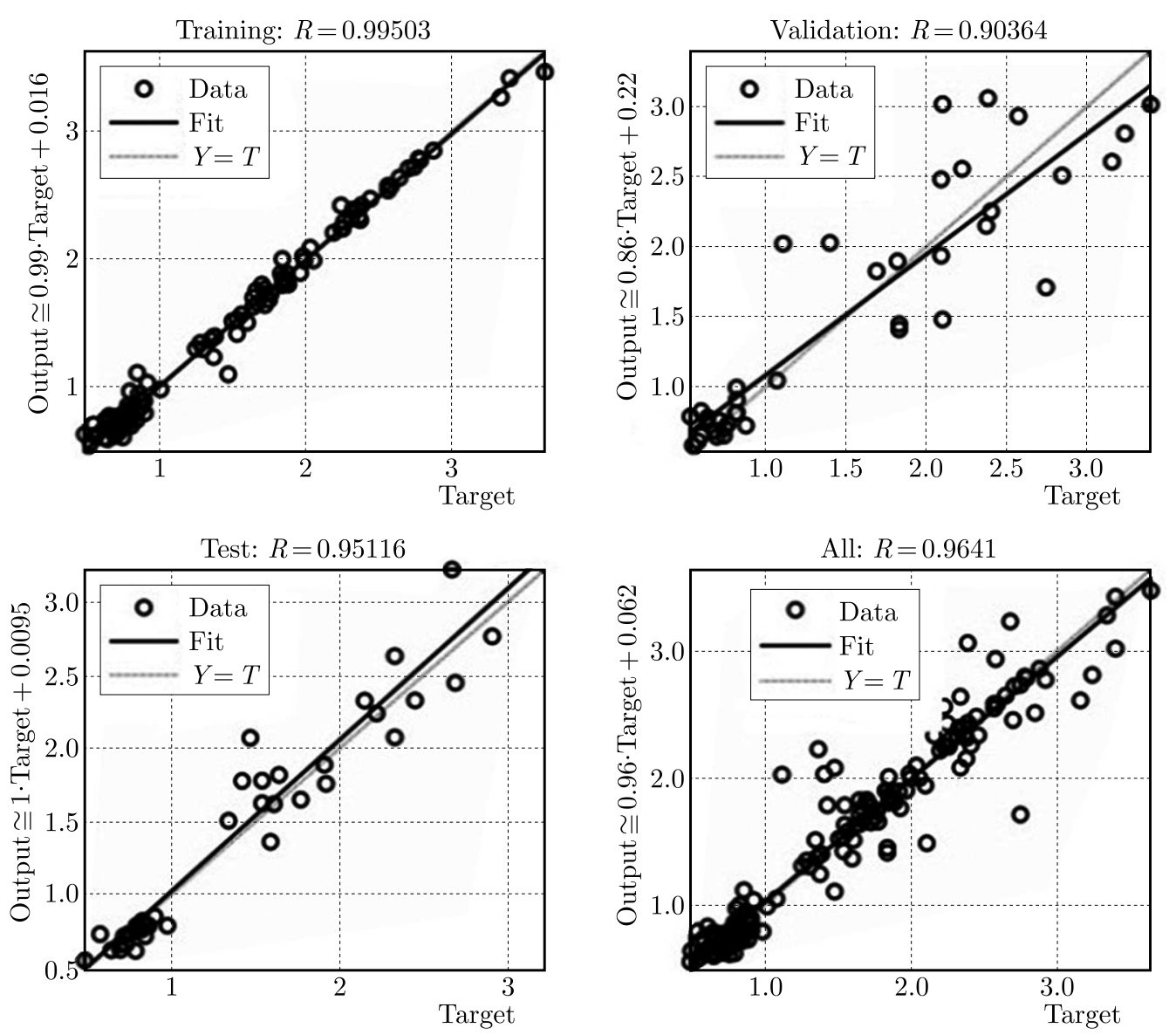

Fig. 10. Regression graph of trained artificial neural network

\section{Selection of appropriate amounts for input parameters}

In this article, two methods are used for the selection of appropriate amount of the input parameters in order to reach the best output amounts. The first method is to predict using a trained ANN and the second one is the Taguchi DOE. It is attempted to reduce the maximum height of wrinkling and keep the FLD criterion below 1 to prevent tearing.

\section{Results and discussion}

As for the Taguchi DOE, graphs which are called signal to noise ratio are obtained. Each of these graphs demonstrates the influence of input parameters on the outputs. In fact, the more differentials in a line, the greater effect of that parameter. In Figs. 11a and 11b, the influence of inputs on the FLD criterion and the maximum wrinkling height are shown, respectively. In Fig. 11a, it can be seen that the blank length is the most effective parameter and friction between the matrix, blank-holder and blank is the least influential parameter among the FLD criterion parameters. Moreover, in Fig. 11b, it is obvious that the blank thickness is the most important, and the blank length is the least important parameter affecting the maximum wrinkling height created on the flanging part of the product.

Regarding prediction of appropriate input parameters by the Taguchi DOE as shown in Table 6, a test with 121331 code is suggested. This code shows the level of each parameter. For example, the aforementioned code shows that friction between the matrix, blank-holder and blank is in the first level which is $0.04 \mathrm{~mm}$, friction between the punch and blank is in the 

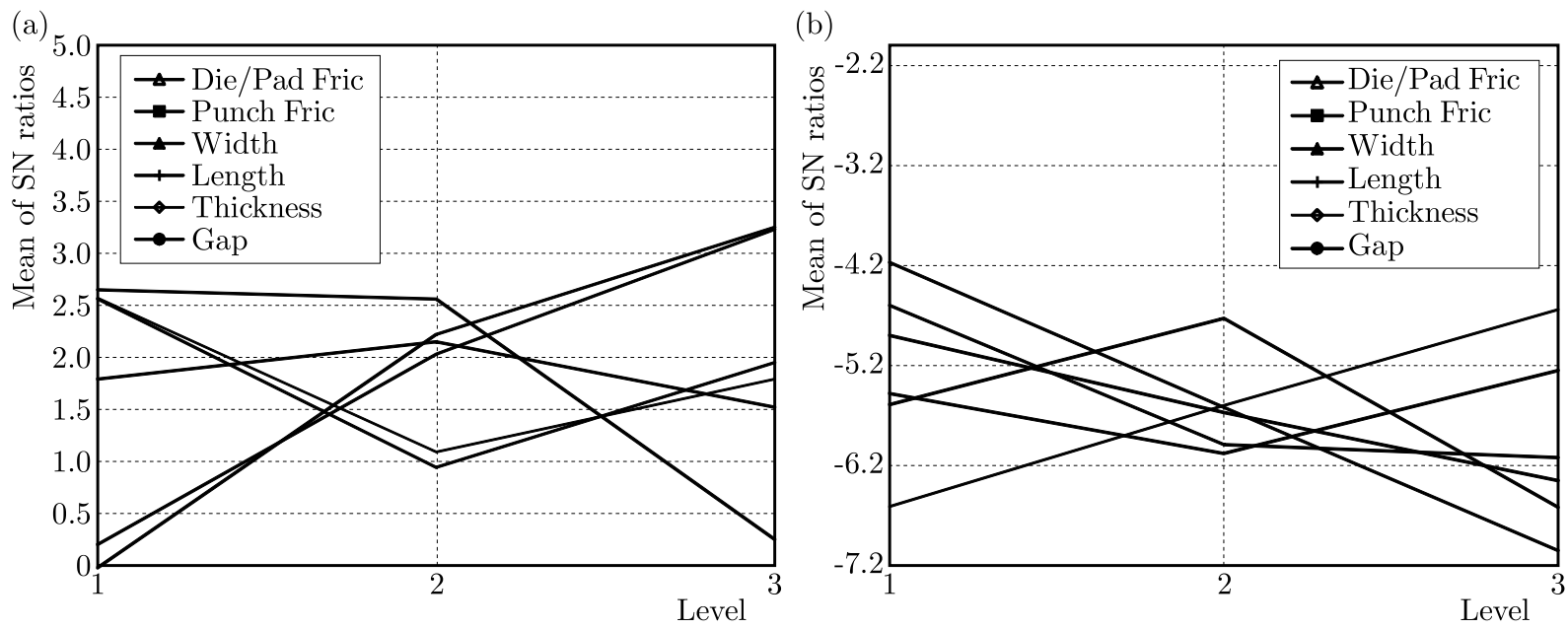

Fig. 11. Influence of input parameters on (a) FLDCRT and (b) maximum wrinkling length

second level which is $0.07 \mathrm{~mm}$, the blank width is in the first level which is $1150 \mathrm{~mm}$. Similarly, the blank height is $1560 \mathrm{~mm}$, blank thickness is $0.09 \mathrm{~mm}$ and the gap between the blank and blank-holder is $0.02 \mathrm{~mm}$. The results which are shown in Table 6 , show that there is a great discrepancy between the Taguchi prediction and FEA, especially for the maximum wrinkling height. Therefore, it could be concluded that the Taguchi DOE would not be a successful method for prediction of input parameters.

Table 6. Comparison between the Taguchi prediction and the finite element for test number 121331

\begin{tabular}{|c|c|c|c|}
\hline Outputs & Taguchi & Finite element & Percentage of error \\
\hline \hline FLD Criterion & 0.597 & 0.657 & 9.13 \\
\hline Wrinkling height & 7.12 & 2.24 & 217.85 \\
\hline
\end{tabular}

On the other hand, the trained ANN predicts the experiment with 231333 code as an appropriate combination of inputs (Table 7). This code shows that friction between the matrix/blankholder and blank is $0.07 \mathrm{~mm}$, friction between the punch and blank is 0.15 , blank width is $1150 \mathrm{~mm}$, blank height is 1560 , blank thickness is 0.9 and the gap between the blank and blankholder is $0.07 \mathrm{~mm}$. By comparing these results with the prediction of Taguchi, the trained ANN has predicted the outputs with a less error. This error for the FLD criterion or the maximum wrinkling height is less than $10 \%$.

Table 7. Comparison between the artificial neural network prediction and finite element for test number 231333

\begin{tabular}{|c|c|c|c|}
\hline Outputs & ANN & Finite element & Percentage of error \\
\hline \hline FLD Criterion & 0.536 & 0.572 & 6.29 \\
\hline Wrinkling height & 1.198 & 1.32 & 9.84 \\
\hline
\end{tabular}

\section{Conclusion}

In this paper, a combination of an experiment, finite element analysis and artificial neural network is used. In fact, based on a finite number of FEA results, which are validated by experiment, an ANN with 2 hidden layers is trained and utilized to predict specified outputs (maximum wrinkling height and tearing) quickly and accurately. First of all, it could be concluded that a 
trained neural network is able to predict outputs with an error of 0.1 (Mean Square Error). The prediction by the trained ANN could be done by less than $10 \%$ and some acceptable error. For this panel, the maximum wrinkling height predicted by the Taguchi DOE shows a great numerical difference with FEA results. Moreover, the results show that by increasing the training data up to $15 \%$ of full factorial DOE, the accuracy of the trained ANN prediction could improve. Also, using the parameters predicted by the trained ANN leads to smaller wrinkling which could be a sign of better quality. Finally, it is inferred that the blank length is the most effective parameter and friction between the matrix, blank-holder and blank is the least important parameter affecting tearing. That the blank thickness is the most effective parameter in the maximum wrinkling height and the blank length is the least effective one.

\section{References}

1. ABAQUS version 6.11 User Manual

2. Candra S., Batan I.M.L., Berata W., Pramono A.S., 2015, Analytical study and FEM simulation of the maximum varying blank holder force to prevent cracking on cylindrical cup deep drawing, Procedia CIRP, 26, 548-553

3. Chamekh A., Salah H.B.H., Hambli R., 2009, Inverse technique identification of material parameters using finite element and neural network computation, International Journal of Advanced Manufacturing Technology, 44, 1/2, 173-179

4. Colgan M., Monaghan J., 2003, Deep drawing process: analysis and experiment, Journal of Materials Processing Technology, 132, 1, 35-41

5. Demirci I.H., Yaşar M., Demiray K., Karali M., 2008, The theoretical and experimental investigation of blank holder forces plate effect in deep drawing process of AL 1050 material, Materials and Design, 29, 2, 526-532, doi:http://dx.doi.org/10.1016/j.matdes.2007.01.008

6. El Sherbiny M., Zein H., Abd-Rabou M., El Shazly M., 2014, Thinning and residual stresses of sheet metal in the deep drawing process, Materials and Design, 55, 0, 869-879, doi:http://dx.doi.org/10.1016/j.matdes.2013.10.055

7. Fereshteh-Saniee F., Montazeran M.H., 2003, A comparative estimation of the forming load in the deep drawing process, Journal of Materials Processing Technology, 140, 1/3, 555-561, doi: http://dx.doi.org/10.1016/S0924-0136(03)00793-3

8. Forouzan S., Akbarzadeh A., 2007, Prediction of effect of thermo-mechanical parameters on mechanical properties and anisotropy of aluminum alloy AA3004 using artificial neural network, Materials and Design, 28, 5, 1678-1684

9. Gao E., Li H., Kou H., Chang H., Li J., Zhou L., 2010, Finite element simulation on the deep drawing of titanium thin-walled surface part, Rare Metals, 29, 1, 108-113

10. Hashemi R., Ghazanfari A., Abrinia K., Assempour A., 2012, Forming limit diagrams of ground St14 steel sheets with different thicknesses, SAE International Journal of Materials and Manufacturing, 5, 2012-01-0018, 60-64

11. Laurent H., Coër J., Manach P., Oliveira M., Menezes L., 2015, Experimental and numerical studies on the warm deep drawing of an Al-Mg alloy, International Journal of Mechanical Sciences, 93, 59-72

12. Padmanabhan R., Oliveira M., Alves J., Menezes L., 2007, Influence of process parameters on the deep drawing of stainless steel, Finite Elements in Analysis and Design, 43, 14, 1062-1067

13. Sezek S., Savas V., Aksakal B., 2010, Effect of die radius on blank holder force and drawing ratio: a model and experimental investigation, Materials and Manufacturing Processes, 25, 7, $557-564$ 
14. Singh C.P., Agnihotri G., 2015 Study of deep drawing process parameters: a review, International Journal of Scientific and Research Publication, 5, 2, 1-15

15. Singh D., Yousefi R., Boroushaki M., 2011, Identification of optimum parameters of deep drawing of a cylindrical workpiece using neural network and genetic algorithm, World Academy of Science, Engineering and Technology, 78, 211-217

16. Watiti V.B., Labeas G.N., 2010, Finite element optimization of deep drawing process forming parameters for magnesium alloys, International Journal of Material Forming, 3, 1, 97-100

17. Wifi A., Abdelmaguid T., 2012, Towards an optimized process planning of multistage deep drawing: an overview, Journal of Achievements in Materials and Manufacturing Engineering, 55, 1, 7-17

18. Yagami T., Manabe K., Yamauchi Y., 2007, Effect of alternating blank holder motion of drawing and wrinkle elimination on deep-drawability, Journal of Materials Processing Technology, 187, 187-191

19. Zein H., El Sherbiny M., AbD-Rabou M., 2014, Thinning and spring back prediction of sheet metal in the deep drawing process, Materials and Design, 53, 797-808

Manuscript received October 28, 2016; accepted for print January 5, 2017 